\title{
Research on the Physical Education Network of Middle School Education
}

\author{
Xinbao $\mathrm{Du}^{1, \mathrm{a}}$ \\ ${ }^{1}$ Department of Wushu, Shenyang Sport University, Shenyang, 110102, China \\ aemail: shenyangtaixie@163.com
}

Keywords: middle school physical education, network education

\begin{abstract}
Network-based physical education in m iddle schools is a new research subject and a new field of $m$ iddle school physical educational re form, playing a very im portant role in the improvement of the overall quality of physical teachers of senior middle schools, the application of information technology, the propelling of $\mathrm{m}$ iddle school students to go deeply into the field of physical education and improvement of humanistic qualities of athletes.
\end{abstract}

\section{OBJECT AND METHOD OF RESEARCH}

\subsection{Object of research}

Make research of the middle school network conditions as well as the network attitude of middle school students through surfing the Internet and making on-line consultation, and understanding the common conditions of schools and universities th rough understanding the current conditions of college and university.

\subsection{Researching method}

\subsubsection{Survey research}

Understand the general conditions of the $45 \mathrm{~m}$ iddle schools' campus networks with the method of surfing the Internet for survey.

\subsubsection{Mathematical statistic method}

Make statistic processing and analyzing to the data achieved through survey.

\subsubsection{Theoretic analyzing method}

Put forward the measures for the development of the physical education of middle schools through using theories and methods in information theory and teaching theory.

\subsubsection{Documental material method}

Make reference to documental materials related to progresses and results of the research of middle school physical education

\section{SURVEY RESULT AND ANALYSIS}

2.1 Conditions of sports web pages in middle schools' websites

\subsubsection{Number of sports websites in middle school's websites}

Among all the middle schools, $85 \%$ have not set sports websites in their websites, and $14.5 \%$ have set sports websites in th eir websites, among which, national level key $m$ iddle schools accounts for 95.3\%, provincial level key $\mathrm{m}$ iddle schools accounts for 3.3\%, and other middle schools accounts for $1.4 \%$, showing that the national level key middle schools attach $\mathrm{m}$ ore importance to the network-based physical education comparatively.

\subsubsection{Columns of the sports web pages in the websites of middle schools}

The columns of the sports web pag es, mainly includes sports news, sp orts competition, sports exercise, sports news and sports consultation, which can generally showing the contents of physical education in middle schools. However, comparing with the needs of middle school students, the number of the columns is smaller and the capacity of columns is lower. Since sports webpage is one of the fastest $\mathrm{m}$ edia in the speed of exchanging inform ation, we should increase the num ber of 
sports webpage columns and enhance their storage capacity.

\subsubsection{Time-lag problem happening to sports web pages in middle schools' websites}

The contents of sports web pages in the middle schools' websites suffer from the time-lag problem and the sports information renewal period is comparatively too long, showing a low er efficiency in spreading and communicating sports information through network. According to survey, satisfaction level of students to the sports web page is com paratively lower, for only $16.2 \%$ of all students said they were satisfied with the sports web page , mainly because of th e lacking in novelty and modernity and dullness in the format of the sports website contents of mi ddle schools, leading to a low acceptance and satisfaction rate among students.

\subsubsection{Information awareness of physical teachers of middle schools}

At present, the physical teach ers of middle schools have recognized the im portance of making active information choosing and communication in increasing their education quality, accumulating their teaching experience and enhancing their teach ing arts. However, since the impacts of various kinds of subjective and objective factors, the information awareness of middle school teachers need to be improved, and to be specific, physical teac hing is conducted mainly in the sports ground, and sports teachers teach students sports skills just through exercising movements without giving much sports information knowledge to students, since the traditional teaching m ode of excess ively stressing on teaching sports movements surely dos e not need $\mathrm{m}$ uch new sports inf ormation to be infused in teaching. However, the course called Sports and Health tells us th at a sports teacher, in the practice of providing guidance to students, on the one hand, is required to provide newest sports information to students, that is to provide students with scientific 'fitness model', on the other hand, should require students to read and 'renew' the 'fitness model' through the tool of infor mation, and students should widen their visu al field with renewed inform ation and be bold in doing sports practice for the culture of their innovative thought, spirit and capacity.

2.2 Factors affecting the developm ent of netw ork-based physical education of $\mathrm{m}$ iddle schools

2.2.1 The level of network-based physical education is more directly and closely related to the level of physical teachers, comparing with other factors

According to the survey made to 132 physical teachers of middle schools in Y ancheng City, Jiangsu Province, among all the ph ysical teachers, $62.4 \%$ of the physical t eachers thought that the establishment and developm ent of network physical education should be done by com puter professionals instead of by physical teachers, $28.5 \%$ of the physical teachers th ought that the network is mainly used to provide sports inform ation consultancy for the specialist of infor mation center, $3.8 \%$ of the phys ical teachers thought that th ey should be involved into the d evelopment of network-based physical education and only $9.6 \%$ of the physical $t$ eachers thought they had the capacity in the developm ent of network physical education while $86.8 \%$ said they did not have enough capacity in the development of network physical education.

\subsubsection{The effect of constructing network software for physical education}

There are $76.5 \%$ of we $b$ pages of $m$ iddle school physical education showing comparatively higher quality in the hardware c onditions, since middle schools consider that the level of hardware platform construction of a school represents the school's quality level, thus making huge investment in the hardware construction. At the sam e time, the middle schools also attached much importance to the software construction, and th e constructed web page of key s ubjects is comparatively higher in quality with uniqu e features, but $\sin$ ce the variety in the idea of physical education development, middle schools generally consider that the physical education just play an adornm ent role in overall education.

\subsubsection{Middle school network monitoring management mechanism}

The Middle school network monitoring management mechanism is the most im portant ring in the realization of network functions. However, many middle schools have the problem of stressing on the on-line clicking volume while ignoring the ne ws renewal of the web pages, stressing on the 
time-effect of opening the networ $\mathrm{k}$, while ignoring $\mathrm{m}$ aking safety monitoring of the network, and stressing on making continuous software upgrading while ignoring making supporting management. The affection of the above factors has led to the raising of various problem s, even computer virus infection, in the networks of a few middle schools.

\subsubsection{Effect of network environment construction}

At present, the sports network of the middle school has merged into the interactive hardware platform of the cam pus network, but under the af fection of traditi onal idea, students are still far from recognizing the interaction fu nction of sports network. Acco rding to a survey, among all the students, $15.4 \%$ of the students often browsed we $\mathrm{b}$ pages of sport contents, $4.8 \%$ of the students considered they needed sports web page, $44.4 \%$ of the students considered they did not necessarily need sports web page, and $50.8 \%$ of the students said they completely did not need the sports web page, from which we can see the importance of th e correction of the stude nts' recognition towards physical network and the construction of a nice on-line environment for physical network.

\section{CONCLUSION AND SUGgestion}

\subsection{Conclusion}

The current conditions of the developm ent of middle school physical network are not optimistic due to the commonly occurred problem $\mathrm{s}$ of oldness in idea and time lag in inf ormation transportation, which has actua lly made negative af fections to the developm ent speed of the physical network of $\mathrm{m}$ iddle schools and has exerte $\mathrm{d}$ limitation to the application of infor mation technology in the physical education process. As a result, we should strengthen the education of middle school physical teachers for the enhancem ent of their information literacy and improvement of their intelligent structures, and help them get the capacities of using modern information tools for making effective 'column classification' and 'formatting' of information, and should use theories and methods of information science to gradually e nhance the skills of stude nts in applying sports information, promote the students to $\mathrm{m}$ anage scientific fitness $\mathrm{m}$ ethod and upraise students' harmonious unity level in their phys ical health, psychological health and social adaptive capacity, thus realizing the objective of the development of the middle school physical network.

\subsection{Suggestion}

\subsubsection{Optimizing information platform of middle school physical network}

Establish quality inform ation platform for the development of the inform ationized services provided by the middle school physical education mainly through the development of the physical education network service content system of middle schools.

\subsubsection{Exerting the functions of the middle school network-based physical education}

Middle school network education can provide sports information resources for students in their individualized learning process, thus realizing the principle of teach ing students in accordance with their aptitudes. Through network education, stude nts can also get best fitness guidance with comparatively lower price, for example, there are a comparative large number of students who want to take part in fitness exercises but have weakness in self-exercise and shortage in guidance, and such problem can be better solved if these students take part in the network education.

\subsubsection{Strengthen the network monitoring management of middle school physical education}

The network $m$ onitoring management of $m$ iddle school physical education does not just involve technical aspects, but instead a synthetic and infor mationized teaching environmental system, including multiple elements, such as network installation, application platform, information resource, management mode, professional application, personnel quality, etc.

\subsubsection{Information skill training for middle school physical teachers}

Strengthen the training of in-ser vice physical education teachers. The sports departm ents of middle schools should attach importance to the culture of $m$ iddle school teachers in their information literacy, have correct knowledge of the importance of the information literacy culture of middle school teachers and adopt feasible $\mathrm{m}$ easures to enhance the $\mathrm{m}$ iddle school teachers' information literacy culture. 
